\title{
Probabilistic seismic hazard assessment of tribal district headquarter Dantewara of Chhattisgarh state (India)
}

\begin{abstract}
Earthquakes, the most dangerous and destructive natural hazards in the globe, manifest themselves in the form of vibrations of the earth which are caused by the sudden release of strain that has accumulated over time. Recent years have witnessed an increase in awareness about earthquake and their causes and mitigations. Seismic Hazard analysis is a method of quantifying the area in terms of topographical and seismological data. In the present paper, an attempt has been made to estimate seismic hazard at bedrock level in terms of PGA using state of art, probabilistic seismic hazard analysis. A detailed catalogue of historical and recent seismicity, within $300 \mathrm{~km}$ radius around the headquarter has been compiled and new seism tectonic map has been generated for the region. The completeness of the data should be checked before carrying out hazard analysis. Finally earthquake data analyzed statistically and the seismicity of the region around district headquarter Dantewara of Chhattisgarh, India, has been evaluated by defining ' $a$ ' and ' $b$ ' parameters of GutenbergRichter recurrence relationship. For district headquarter Dantewara, Values of the Peak Ground Acceleration (P.G.A.) for M100 Earthquake, has been estimated. The outcome of the research in the present paper, clearly indicate that the maximum (Peak Ground Acceleration) PGA values for the site of Dantewara, was obtained, due to fault No. 8.
\end{abstract}

Keywords: deterministic, probabilistic approach, seismic hazard study, seismic source models
Volume 4 Issue I - 2018

\author{
Ashish K Parashar,' S Atmapoojya, ${ }^{2}$ SS \\ Rathore $^{2}$ \\ 'Department of Civil Engineering, GGV Central University, India \\ ${ }^{2}$ Department of Civil Engineering, Kavikulguru Institute of \\ Technology and Science, India
}

Correspondence: Ashish K Parashar, Department of Civil Engineering, IT, GGV, Central University, Bilaspur, Chhattisgarh, India,Tel 094-255-025-72, Email aparashar08@gmail.com

Received: August 27, 2017| Published: January 17, 2018
Abbreviations: DHSA, deterministic seismic hazard analysis; PGA, peak ground acceleration

\section{Introduction}

Dantewara District or Dakshin Bastar District is situated in the State of Chhattisgarh in Indian. The district is part of Bastar Division. Until 1998, the Dantewara District was a tehsil of the larger Bastar District. Dantewara District has an area of $10,238.99 \mathrm{~km}^{2}$. It is bounded on the north and northeast by Bastar District, on the east by Malkangiri District of Orissa state, on the south and southwest by Khammam District of Andhra Pradesh state, and on the west by the Indravati River, which forms the boundary with Karimnagar District of Andhra Pradesh and Gadchiroli District of Maharashtra. The district has a population of 719,065 (2001 census), of which 476,945 (66\%) are tribal peoples. After declaration of district in Dantewara, the construction activities have suddenly increased. So it is essential to pay attention towards earthquake Disaster and its mitigation. Earthquakes are common phenomena which occur most often irrespective of time and place. They are most feared amongst all natural hazards as they strike suddenly without any prior indication and create devastation to life and property. They are not yet predictable; hence prior warning to people is not possible. Earthquakes are not killer by themselves but houses in which people reside kill them. During an earthquake poorly designed and built houses on weak foundation collapse and sometimes associated fire hazards kill the residents.

India is highly vulnerable to earthquakes, with more than $60 \%$ of the land being prone to tremors of Richter Intensity 7.0 and greater, that can cause structural damage. Earthquakes continue to cause largescale human fatalities, most of which are due to collapse of man-made structures. Recent earthquakes have revealed the under-preparedness of the country in facing its impacts. Since short- or mid-term prediction of earthquakes is difficult, seismic safety of built environments will ensure that, the structures do not collapse, this forms an important cornerstone of earthquake disaster mitigation efforts. Poor people in developing countries are particularly vulnerable to disasters because of where they live. Research shows that they are more likely to occupy dangerous locations, such as flood plains, river banks, steep slopes, reclaimed land and highly populated settlements of flimsy shanty homes. To evaluate the seismic hazards for a particular site or region, all possible sources of seismic activity must be identified and their potential for generating future strong ground motion needs to be evaluated. Identification of seismic sources requires some detective work, nature's clues, some of which are obvious and others quite obscure, must be observed and interpreted. Seismic Hazard Analysis involves the quantitative estimation of ground-shaking hazards at a particular site. In the present study Seismic Hazard Analysis (SHA) has been used to assess Peak Ground Acceleration for District Headquarter Dantewara ( $\left.18^{\circ} 54^{\prime} \mathrm{N}-81^{\circ} 21^{\prime} \mathrm{E}\right)$ of Chhattisgarh state.

\section{Identification and characterization of sources}

In present study District Headquarter Dantewara was selected as the target, including a control region of radius $300 \mathrm{~km}$ around the District Headquarter, having centre at $18^{\circ} 54^{\prime} \mathrm{N}-81^{\circ} 21^{\prime} \mathrm{E}$, for further 
investigation. The fault map of this circular region was prepared in reference with the Seismo-tectonic Atlas of India (2000), is as shown in Figure 1. From Figure 1, it is obvious that in recent years seismic activity appears to be concentrated along Kaddam Fault $(174 \mathrm{~km})$, Kinnerasani - Godavari Fault $(228 \mathrm{~km})$, Godavari Valley Fault(130km), Kolleru Lake Fault $(129 \mathrm{~km})$, Kanada Fault $(32 \mathrm{~km})$, Parvatipuram- Bobbili Fault $(121 \mathrm{~km})$, Nagavali Fault $(46 \mathrm{~km})$ and Vamsadhara Fault $(51 \mathrm{~km})$. A total of Thirteen (13) major faults, which influence seismic hazard at District Headquarter Dantewara, were identified in the above map. Fault details are tabulated in Table 1. After going through various available literatures and sources such as (USGS, NIC), 66 Nos. of Earthquakes in the magnitude range $3<$ $\mathrm{Mw}<6$ for District Headquarter Dantewara, occurring over the period from 1827 to 1898 were identified in the present study (Figure $1 \&$ Table 1).

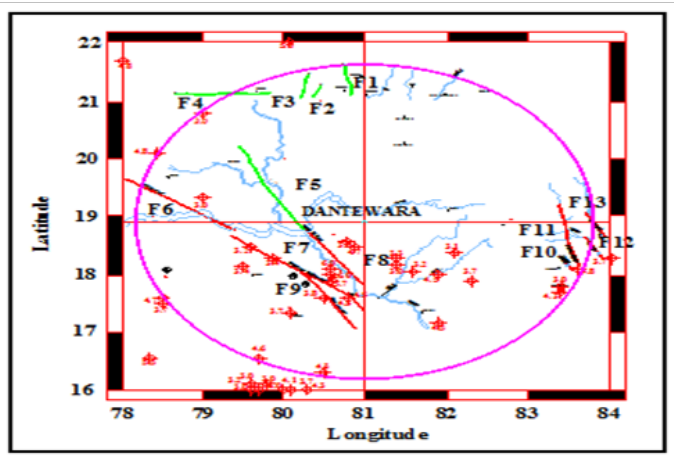

Figure I Faults of District Headquarter Dantewara and its Surroundings.

Table I District Headquarter Dantewara Faults Considered for Hazard Analysis

\begin{tabular}{lllll}
\hline Fault No. & $\begin{array}{l}\text { Fault } \\
\text { length } \\
(\mathbf{k m})\end{array}$ & $\begin{array}{l}\text { Min.map } \\
\text { distance } \\
(\mathbf{k m})\end{array}$ & $\begin{array}{l}\text { Focal } \\
\text { depth } \\
(\mathbf{k m})\end{array}$ & $\begin{array}{l}\text { Hypo } \\
\text { central } \\
\text { distance } \\
(\mathbf{k m})\end{array}$ \\
\hline FI & 58 & 242.975 & 10 & 243.181 \\
F2 & 25 & 247.616 & 10 & 247.818 \\
F3 & 45 & 251.265 & 10 & 251.464 \\
F4 & 125 & 276.012 & 10 & 276.194 \\
F5 & 180 & 81.862 & 10 & 82.471 \\
F6 & 174 & 170.93 & 10 & 171.223 \\
F7 & 228 & 126.727 & 10 & 127.121 \\
F8 & 130 & 71.588 & 10 & 72.284 \\
F9 & 129 & 128.103 & 10 & 128.493 \\
FI0 & 32 & 265.117 & 10 & 265.306 \\
FII & 121 & 257.837 & 10 & 258.031 \\
FI2 & 46 & 291.139 & 10 & 291.311 \\
FI3 & 51 & 290.698 & 10 & 290.87 \\
\hline
\end{tabular}

\section{Catalogue completeness and seismicity parameter}

In 1972, Steep proposed a method based on the length of the period over which a particular magnitude is complete. In this method, catalogues are grouped into several magnitude ranges and each magnitude range is considered as a point process in time. As a first step for the evaluation of the completeness period, the number of earthquakes reported during each decade for the given magnitude ranges were evaluated. The plot showing the variation of $\sigma \lambda$ with time is given in Figure 2. The earthquake data is considered as complete, as long as its variation is along the 1/T line. The plotted points are assumed to have a straight line, following a slope as long as the data becomes complete. From Figure 2, it is clear that the magnitude range 3 - 3.9 is complete for 30 years, 4 - 4.9 is complete for 60 years, 5-5.9 is complete for 90 years and 6- 6.9 is complete for 140 years (Table 2).

$$
\log _{10}(N)=3.8591-0.6974 M_{w} \log _{10}
$$

Norm of residuals $\left(\mathrm{R}^{2}\right)=0.80361$

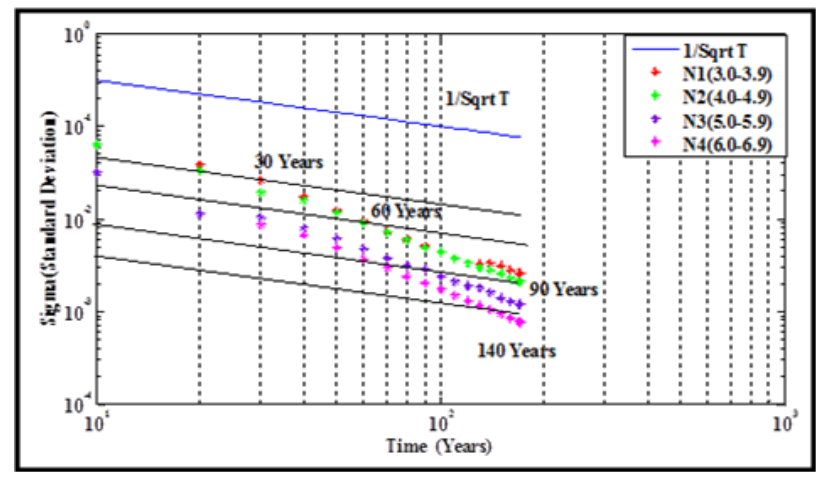

Figure 2 Completeness Test of Earthquake Data for District Headquarter Dantewara.

Table 2 Activity Rate and Interval of Completeness for District Headquarter Dantewara

\begin{tabular}{llll}
\hline $\begin{array}{l}\text { Magnitude } \\
\text { Mw }\end{array}$ & $\begin{array}{l}\text { No of events } \\
\geq \text { Mw }\end{array}$ & $\begin{array}{l}\text { Complete in } \\
\text { interval (year) }\end{array}$ & $\begin{array}{l}\text { No. of events } \\
\text { per year } \geq \text { Mw }\end{array}$ \\
\hline 3 & 66 & 30 & 2.2 \\
4 & 33 & 60 & 0.55 \\
5 & 10 & 90 & 0.1112 \\
6 & 3 & 140 & 0.0215 \\
\hline
\end{tabular}

\section{Estimation of maximum magnitude}

In seismic hazard analysis, the knowledge of estimating the maximum magnitude is important and used as one of the key input parameters in the seismic design. It indicates the highest potential of accumulated strain energy to be released in the region or a seismic source/fault. Alternatively, the Mmax is an upper limit or the largest possible earthquake that may produce the highest seismic hazard scenarios of the region. However, in the study region, very limited amount of data is available for the last few decades (based on the instrumental recorded data), which do not sufficiently reveal the full seismic potential characteristics of any seismic source/fault with confidence. Further, there is no well known or well defined methodology available for evaluation of maximum magnitude. ${ }^{1}$ Some of the methods have been proposed by various researchers such as Kijko \& Sellevol ${ }^{2}$ Wells and Coppersmith, Gupta, and Mueller. In the present work, Mmax is estimated considering two approaches. These are using fault rupture relationship (Wells and Coppersmith and by adding incremental values. To determine the maximum magnitude of a fault or source, Wells and Coppersmith proposed some empirical equations based on the subsurface fault rupture characteristics such as length, area and slip rate of the fault with the moment magnitude. 
These empirical equations were developed by standard statistical regression using a global database of the events. These relations are given based on tectonic regime characteristics such as strike-slip, reverse, and normal faulting and also the average relation for all slip types are developed to be appropriate for most application in general (if the fault type is unknown). In this work, the length of faults was estimated from the seism tectonic atlas (SEISAT-2000) of India published by GSI (Geological Survey of India) and some of the faults were extracted from the literature. The relation proposed by Wells and Coppersmith to estimate expected moment magnitude of a linear fault is given below:

$$
\log (S R L)=0.57 M_{w}-2.33
$$

The relation between $\mathrm{Mw}$ and surface rupture length (SRL) was developed using reliable source parameters and this is applicable for all types of faults, shallow earthquakes, and interplate or intraplate earthquakes (Wells and Coppersmith 1994). Using this equation along with a parametric study, it is observed that the subsurface fault rupture length of about $3.8 \%$ of the total fault length provides moment magnitude values closely matching those of the past earthquakes. The estimation procedure is presented in tabular form in Table 3. In places where the magnitude of any event was not available in the previous reports, they were derived using the approximate empirical relation $[\mathrm{m}=(2 / 3) \mathrm{I}[0+1]$ using the reported maximum MMI number. To avoid further confusion associated with different magnitude scales, all moment magnitude Mw were converted to Maximum Magnitude (M). In this method to estimate Mmax an increment of 0.5 is added to the observed maximum magnitude (Table 3).

Table 3 Estimation of Maximum Magnitude for Faults/Lineaments for District Headquarter Dantewara

\begin{tabular}{lllll}
\hline Fault & $\begin{array}{l}\text { Fault } \\
\text { length } \\
\text { (km) }\end{array}$ & $\begin{array}{l}\text { Method } \\
\text { A (well \& } \\
\text { Coppersmith } \\
\text { 1994) }\end{array}$ & $\begin{array}{l}\text { Method -B } \\
\text { Mmax by } \\
\text { incremental } \\
\text { value (Gupta } \\
\text { 2002) }\end{array}$ & $\begin{array}{l}\text { Mmax } \\
\text { considered } \\
\text { for the } \\
\text { present } \\
\text { study (M) }\end{array}$ \\
\hline FI & 58 & 4.7 & 6.3 & 6.3 \\
F2 & 25 & 4.1 & 6.3 & 6.3 \\
F3 & 45 & 4.5 & 6.3 & 6.3 \\
F4 & I25 & 5.3 & 3.5 & 5.3 \\
F5 & 180 & 5.6 & 3.5 & 5.6 \\
F6 & 174 & 5.6 & 3.5 & 5.6 \\
F7 & 228 & 5.8 & 5 & 5.8 \\
F8 & I30 & 5.4 & 6.5 & 6.5 \\
F9 & 129 & 5.3 & 4.3 & 5.3 \\
FI0 & 32 & 4.3 & 5.3 & 5.3 \\
FII & 121 & 5.3 & 5.3 & 5.3 \\
FI2 & 46 & 4.6 & 4.2 & 4.6 \\
FI3 & 51 & 4.6 & 4.2 & 4.6 \\
\hline
\end{tabular}

\section{Deaggregation of regional hazards}

Finally the Deterministic Seismic Hazard Analysis (DHSA) was carried out for Kodar Dam Site considering the seismic events and Seism tectonic sources from the newly developed seism tectonic model for the region, $300 \mathrm{~km}$ around the Kodar Dam Site. The maximum possible earthquake magnitude for each of the seismic sources within the area was then estimated. Shortest distance to each source and site of interest was evaluated and taken as major input for performing DHSA. In the present investigation truncated exponential recurrence model developed by Mcguire \& Arabasz (1990) was used and is given by following expression;

$$
\ddot{\mathrm{e}}_{\mathrm{m}}=\mathrm{N}_{\mathrm{i}}(m 0) * v * \frac{\exp \left[-\beta\left(m-m_{o}\right)\right]-\exp \left[-\beta\left(m_{\max }-m_{o}\right)\right]}{1-\exp \left[-\beta\left(m_{\text {max }}-m_{o}\right)\right]}
$$

Where $\tilde{\mathrm{o}}=\exp (\alpha-\beta * \mathrm{~m} 0), \alpha=2.303^{*} \mathrm{a}, \beta=2.303^{*} \mathrm{~b}$ and $\mathrm{Ni}(\mathrm{m} 0)$ is the weightage factor for a particular source based on recurrence. The threshold value having a magnitude 3.0 was adopted in the study (Figure 3).

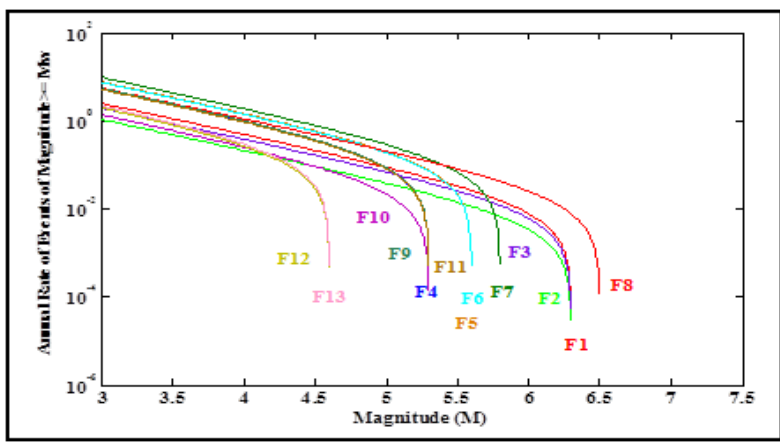

Figure 3 Deaggregation of Seismic Sources near District Headquarter Dantewara.

\section{Ground motion attenuation and estimation of peak ground acceleration (PGA)}

For the present study attenuation relationship suggested by $\mathrm{RN}$ Iyengar \& STG Raghukant ${ }^{4}$ (Applicable for peninsular India, under bed rock condition) has been used.

In

$$
(P G A / g)=C 1+C 2(m-6)+C 3(m-6) 2-\ln (R)-C 4(R)+\ln e
$$

Where,

$$
C 1=1.6858, C 2=0.9241, C 3=0.0760, C 4=0.0057 \text {, }
$$

$\mathrm{R}=$ Hypo central distance, $\mathrm{m}=$ magnitude, $\varepsilon=0$ (for DSHA) 50 Percentile, $\ln \varepsilon=0.4648$ (for DSHA) 84 Percentile

The above attenuation relation is valid for hard rock exposed on the surface, with V s nearly equal to $3.6 \mathrm{~km} / \mathrm{s}$ (Table 4).

Table 4 Deterministic PGA Values at District Headquarter Dantewara

\begin{tabular}{lllll}
\hline $\begin{array}{l}\text { Fault } \\
\text { No. }\end{array}$ & $\begin{array}{l}\text { Fault } \\
\text { length }(\mathbf{k m})\end{array}$ & $\begin{array}{l}\text { Hypo central } \\
\text { distance }(\mathbf{k m})\end{array}$ & PGA values $(\mathrm{g})$ ( 100Years) \\
\hline & & & 50 Percentile & 84 Percentile \\
FI & 58 & 243.181 & 0.00528 & 0.00841 \\
F2 & 25 & 247.818 & 0.00381 & 0.00607 \\
F3 & 45 & 251.464 & 0.0045 & 0.00715 \\
F4 & 125 & 276.194 & 0.00196 & 0.00312 \\
F5 & 180 & 82.471 & 0.02665 & 0.04242 \\
\hline
\end{tabular}




\begin{tabular}{lllll}
\multicolumn{5}{l}{ Table Continues... } \\
\hline $\begin{array}{l}\text { Fault } \\
\text { No. }\end{array}$ & $\begin{array}{l}\text { Fault } \\
\text { length }(\mathbf{k m})\end{array}$ & $\begin{array}{l}\text { Hypo central } \\
\text { distance } \mathbf{( k m )}\end{array}$ & \multicolumn{2}{l}{ PGA values $(\mathbf{g})$ ( I 00Years) } \\
\hline F6 & 174 & 171.223 & 0.0077 & 0.01226 \\
F7 & 228 & 127.121 & 0.0162 & 0.02579 \\
F8 & 130 & 72.284 & 0.06211 & 0.09887 \\
F9 & 129 & 128.493 & 0.00973 & 0.01549 \\
FI0 & 32 & 265.306 & 0.00192 & 0.00305 \\
FII & 121 & 258.031 & 0.00232 & 0.00369 \\
FI2 & 46 & 291.311 & 0.0008 & 0.00127 \\
FI3 & 51 & 290.87 & 0.00081 & 0.00128
\end{tabular}

\section{PSHA method}

Considering the randomness in the occurrence of earthquakes with respect to time, space and magnitude as well as the various other sources of uncertainties, probabilistic concepts and statistical methods are the appropriate tools for the assessment of seismic hazard. PSHA methodology was first proposed by Cornell (1968) to quantify the seismic hazard at a site of interest in terms of a probability distribution. In contrast to DSHA in which seismic hazard is based on a single earthquake scenario, PSHA integrates the effects of all future earthquakes of all possible magnitudes, at all significant distances from the site. Besides, random nature of earthquake occurrences and uncertainty in attenuation of ground motion are taken into consideration in PSHA. As a result, instead of discrete, single-valued event and model used in DSHA, PSHA allows the use of continuous, multi-valued events and models. The seismic hazard needs to be based on a method which properly accounted for the intrinsic uncertainties associated with earthquake phenomena. Since then, both seismological and geological techniques and understanding applied to seismic hazard analysis have improved steadily, so that current practice is now able to utilize information from a variety of both seismological and geological data sources with due considerations for uncertainties. It is acknowledged that uncertainties are vital in the definition of all elements that go into seismic hazard analysis since, the uncertainties often drive the results, and increasingly so for lowexceedance probabilities. The probabilistic analysis allows the use of multi-valued or continuous model parameters. The probability of different magnitude or intensity earthquakes occurring is included in the analysis. Another advantage of probabilistic seismic hazard analysis is that it results in an estimate of the likelihood of earthquake ground motions or other damage measures occurring at the location of interest. It allows for the more sophisticated incorporation of seismic hazard into seismic risk estimates. Probabilistic seismic hazard estimates can be expanded to define seismic risk.

\section{Probability density function of magnitude}

Each source is capable of producing earthquakes with a variety of magnitudes with an upper bound of maximum moment magnitude (Mw, max) and a common lower bound of the threshold magnitude $(\mathrm{mo}=3.0)$. The total range of earthquake magnitudes is divided into 4 equal intervals for all the sources (Table 5). The source can experience an earthquake of any magnitude within the predicted minimum and maximum range for that particular source. This uncertainty in the magnitude of the earthquake is accounted by, the probability of occurrence of a particular magnitude in the given range. All source zones have a maximum earthquake magnitude that cannot be exceeded; in general, the source zone will produce earthquakes of different sizes up to the maximum earthquake, with smaller earthquakes occurring more frequently than larger ones. A basic assumption of PSHA is that, the recurrence law obtained from past seismicity is appropriate for the prediction of future seismicity. In most PSHA's, the lower threshold magnitude is set at values from about 3.0 to 7.0 since magnitudes smaller than that seldom cause significant damage. For each source, the probability of occurrence of an earthquake of a particular magnitude is obtained using the probability density function of the magnitude.

Table 5 Mean of Earthquake Magnitudes

\begin{tabular}{lllll}
\hline mI-mu & $\mathbf{3 . 0 - 4 . 0}$ & $\mathbf{4 . 0 - 5 . 0}$ & $\mathbf{5 . 0 - 6 . 0}$ & $\mathbf{6 . 0 - 7 . 0}$ \\
\hline Mean $(\mathrm{m})$ & 3.5 & 4.5 & 5.5 & 6.5 \\
\hline
\end{tabular}

The distribution with an upper bound magnitude is given by:

$$
\begin{gathered}
f_{M}(m)=\frac{\beta e^{-\beta\left(m-m_{\min }\right)}}{\left[1-e^{-\beta\left(m_{\max }-m_{\min }\right)}\right]} m_{\min } \leq m \leq m_{\max } \\
P\left[m_{1}<m<m_{2}\right]=\int_{m_{1}}^{m_{2}} f_{M}(m) d m \approx f_{M}\left(\frac{m_{1}+m_{2}}{2}\right) x\left(m_{2}-m_{1}\right)
\end{gathered}
$$

\section{Ground motion attenuation relationships}

In the estimation of ground motion parameters at the site of interest, there are inherent uncertainties which must be accounted for, in the computation of seismic hazards. The ground motion parameters are usually assumed to be long normally distributed meaning that the logarithm of the parameters is normally distributed. For accounting this uncertainty in the seismic hazard analysis, the probability distribution of the ground motion parameter Y must be estimated as a function of earthquake source properties (magnitude) and the location of the rupture with respect to the site of interest. The probability of excedences of $Y$ from a certain value $y^{*}$, for a particular source-to-site distance, $r$ and an earthquake of magnitude, $m$ is expressed (Kramer 1996) as: Effects $-\mathrm{P}[\mathrm{Y}>\mathrm{y} * \mathrm{~m}, \mathrm{r}]=1-\mathrm{Fy}\left(\mathrm{y}^{*}\right)$ Attenuation Relationship Where $\mathrm{Fy}(\mathrm{y})$ is the CDF of $\mathrm{Y}$ at $\mathrm{m}$ and $\mathrm{r}$. Timing $\mathrm{P}=1-\mathrm{e}^{-{ }^{\lambda t}}-$ Poisson model. 5

If the site of interest is subjected to shaking from more than one site (say Ns Sources), then

$$
\lambda_{y^{*}}=\sum_{i=1}^{N_{s}} v_{i} \iint P\left[Y>y^{*} \mid m, r\right] f_{M i}(m) f_{R i}(r) d m d r
$$

For realistic cases, PDF's for M (Magnitude) and R (Source to Site Distance) are too complicated to integrate analytically. Therefore, we do it numerically. Dividing the range of possible magnitudes and distances into NM and NR increments, respectively and given (Figure 4).

$$
\lambda y^{*}=\sum_{i=1}^{N S} \sum_{j=1}^{N M} \sum_{k=1}^{N R} v_{i} \iint P\left[Y>\left.y^{*}\right|_{\left.m_{j}, r_{k}\right] P\left[M={ }_{m j}\right] P\left[R=r_{k}\right]}\right.
$$

Final PSHA Equation is given by

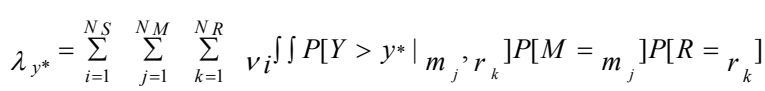

Many researchers have adopted this methodology for evaluating hazard and recently this method has been adopted by Iyengar \& Ghosh, ${ }^{6}$ Raghu Kanth \& Iyengar, ${ }^{7}$ Ambazhagan et al., ${ }^{8}$ and Vipin for the probabilistic seismic hazard analysis of Delhi, Mumbai, Bangalore and Peninsular India respectively. Seismic hazard curve gives a strong 
basis for analyzing the seismic hazard potential at a site. The seismic hazard curve presented in Figure 5 gives the probability of exceedance of certain PGA level (from $0.01 \mathrm{~g}$ to $0.2 \mathrm{~g}$ where $\mathrm{g}=9.81 \mathrm{~m} / \mathrm{s}^{2}$ ) at the centre of district headquarter Dantewara in 1 year, 50 years and 100 years. $^{9-13}$

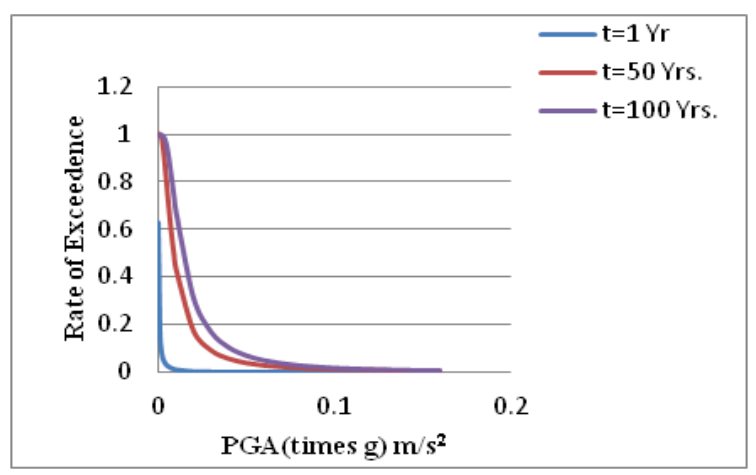

Figure 4 Seismic Hazard Curve.

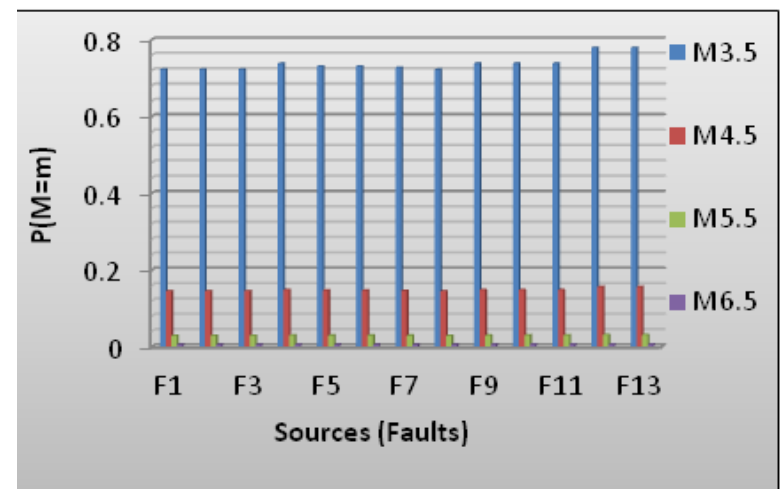

Figure 5 Probability density function of Magnitude.

\section{Conclusion}

The analysis of Probabilistic and Deterministic seismic hazard was carried to determine peak ground accelerations at district headquarter Dantewara, at bed rock level. The Regional Recurrence Relationship obtained for District Headquarter Dantewara has been presented in Equation No 1. And the obtained "b" value is 0.6974 . The probability density function for magnitude lends credible support to the frequent occurrence of moderate earthquakes and occasional occurrence of disastrous earthquakes. Earthquake source F8 and F5 were found to be more dangerous, compared to the other sources as these two could induce magnitude above 5.0 which is disruptive. Hence, the site is situated in less seismically active zone. For district headquarters Dantewara, Values of the Peak Ground Acceleration (P.G.A.) for M100 Earthquake, has been presented in Table 4. The Maximum values of Peak Ground Acceleration (P.G.A.) for Site, obtained due to fault No. 8 (length $130 \mathrm{~km}$, Distance $72.2840 \mathrm{~km}$ ) are $0.06211 \mathrm{~g}$ and $0.09887 \mathrm{~g}$ for 50 Percentile and 84 Percentile respectively. Where Peak Ground Acceleration (P.G.A.) for fault No. 5 (length $180 \mathrm{~km}$, Distance $82.4710 \mathrm{~km}$ ) are 0.02665 gand $0.04242 \mathrm{~g}$ respectively. As far as safety of vital public structures against seismic hazard is considered, it is essential to make sure that construction sites are far away from the active faults. Thus, it can be concluded that the outcome of present study verifies and endorses the Indian Standard zone classification (Appendix 1). ${ }^{14-16}$

\section{Acknowledgements}

None.

\section{Conflicts of interest}

None.

\section{Funding}

None.

\section{References}

1. Ruff L, Kanamori H. Seismicity and subduction processes. Physics of the Earth and Planetary Interiors. 1980;23(3):240-252.

2. Kijko A, Sellevoll MA. Estimation of earthquake hazard parameters from incomplete data files. Part I, Bull Seismol Soc Am. 1989;79:645-654.

3. Narula PL, Acharyya SK, J Banerjee. Seismotectonic Atlas of India and Its Environs. Geological Survey of India, India; 2000.

4. Iyenger RN, Raghukant STG. Attenuation of Strong Ground Motion in Peninsular India. Seismological Research Letters. 2004;75(4):530-539.

5. Guha SK, Basu PC. Catalogue of earthquakes (M3.0) in Peninsular India. Atomic Energy Regulatory Board, Tech. Document No. TD/CSE-1, p. 1-70. 1993.

6. Iyenger RN, Ghose S. Microzonation of Earthquake Hazard in Greater Delhi Area. Current Science. 2004;87(9):1193-1201.

7. Iyengar RN, Raghu Kanth STG. Seismic Hazard Estimation for Mumbai city. Current Science. 2006;91(11):1486-1494.

8. Chandra U. Earthquakes of Peninsular India - A seismotectonic study. Bull Seismol Soc Am. 1977;67(5):1387-1413.

9. Anbazhagan P, Sitharam TG. Seismic Microzonation of Bangalore, India Journal of Earth Systems Science. 2008;117(S2):833-852.

10. IS. Indian Standard Criteria for Earthquake Resistant Design of Structures, Fifth Revision, Part-1, Bureau of Indian Standard, New Delhi, India; 1893.

11. RN Iyenger, S Ghose. Microzonation of Earthquake Hazard in Greater Delhi Area. Current Science. 2004;87(9):1193-1201.

12. STG Raghukanth, Development of Probabilistic Seismic Hazard Map of India Appendix - I, Catalogue of Earthquakes of Moment Magnitude $\geq 4.0$ in and around India Assembled from Eighteen Sources (38860 events including Foreshocks and Aftershocks)

13. Kennedy RP. Ground motion parameters useful in structural design. Presented at the Conference on Evaluation of Regional Seismic Hazards and Risk, Santa Fe, New Mexico; 1980.

14. Rao BR, Rao PS. Historical seismicity of Peninsular India. Bull Seismol Soc Am. 1984;74(6):2519-2533.

15. Raghu Kanth STG. Engineering seismic source models and strong ground motion. Ph.D thesis, Indian Institute of Science, Bangalore, India; 2005.

16. Stepp JC. Analysis of completeness of the earthquake sample in the Puget sound area and its effect on statistical estimates of earthquake hazard. In International Conference on Microzonation II. 1972. p. 897-909. 